\title{
LA SITUACIÓN SOCIO, ECONÓMICA DE LOS JÓVENES HIJOS DE INMIGRANTES HUANCAVELICANOS ASENTADOS $^{40}$ \\ Jorge Constantino Escobar Galván ${ }^{41}$ \\ Facultad de Antropología de la Universidad Nacional del Centro del Perú
}

\begin{abstract}
RESUMEN.
La presente investigación da a conocer las principales características socio-económicas de los jóvenes hijos de inmigrantes huancavelicanos asentados en el distrito de Chilca - Huancayo. Se toma en cuenta sus siguientes aspectos: datos socioeconómicos, tradición familiar, imagen y relaciones con los padres, imágenes y recuerdos de la infancia, escuela, trabajo, imagen de sí mismo, imágenes y percepciones sociales, experiencia religiosa y proyección al futuro. Se combina el método cuantitativo y el método cualitativo. La información fue proporcionada por 40 jóvenes de ambos sexos que participaban en los talleres que el ONG UCSICEP organizaba todos los sábados, pero para efectos de la presente investigación, estos jóvenes fueron trasladados a la Ciudad Universitaria de la Universidad Nacional del Centro del Perú, en cuyos ambientes, cada uno de estos jóvenes desarrolló un cuestionario previamente diseñado por el autor y el equipo de UCSICEP.
\end{abstract}

Palabras Clave: Migración, juventud, violencia política, pobreza, sueños, costumbres.

\section{YOUNG CHILDREN'S SOCIO ECONOMIC SITUATION FOR IMMIGRANTS OF HUANCAVELICA SETTLED IN THE DISTRIC OF CHILCA - HUANCAYO}

\begin{abstract}
This study aims to identify the main socio-economic characteristics of young children of Huancavelica immigrants settled in the district of Chilca - Huancayo. It takes into account the following aspects: socio-economic, family tradition, image and relationships with parents, childhood pictures and memories, school, work, self-image, image and social perceptions, religious experience and future projections. Combines quantitative and qualitative method. The information was provided by 40 young men and women who participated in the workshops organized every Saturday by the NGO UCSICEP, but for the purposes of this research, these youths were transferred to the university campus, National University of Central Peru, in whose environments, each of these young people developed a questionnaire previously designed by the author and UCSICEP team.
\end{abstract}

Key words: Migration, youth, political violence, poverty, dreams, customs.

\footnotetext{
${ }^{40}$ Trabajo de investigación fue recibido el 07/05/2010 retornado para su revisión el 15/06/2010 y aprobado para su publicación 16/11/2010. 


\section{INTRODUCCIÓN}

La investigación realizada estudia las principales características socio-económicas de los jóvenes hijos de inmigrantes huancavelicanos asentados en el distrito de Chilca - Huancayo. Busca responder a las siguientes interrogantes: ¿cuáles son las características socioeconómicas de los jóvenes hijos de inmigrantes huancavelicanos? ¿Por qué migraron sus padres? ¿Cuándo migraron?, ¿Cuáles son los cambios y las transformaciones que han producido los procesos migratorios tanto en el lugar de origen como en el lugar de destino?, ¿Cuál es la importancia de las redes que tejen los potenciales migrantes?, ¿Cuáles son sus principales sueños, esperanzas, etc.?, entre otros.

Es preciso señalar, que el estudio de la migración es importante porque desempeña un papel clave en la mayoría de las transformaciones sociales contemporáneas. Las migraciones son simultáneamente el resultado del cambio global, y una fuerza poderosa de cambios posteriores, tanto en las sociedades de origen como en las receptoras. Sus impactos inmediatos se manifiestan en el nivel económico, aunque también afecta a las relaciones sociales, la cultura, la política nacional e incluso las relaciones internacionales. Las migraciones conducen inevitablemente a una mayor diversidad étnica y cultural en el interior de los países, transformando las identidades y desdibujando las fronteras tradicionales ${ }^{42}$.

Las hipótesis que se han trabajado son las siguientes:

- La principal causa de la migración interna y externa de los jóvenes hijos de inmigrantes huancavelicanos residentes en el distrito de Chilca - Huancayo, está representada por las escasas oportunidades laborales ofrecidas por sus localidades de origen. Además, la migración se vio incentivada por la irrupción de la violencia política y la influencia de los medios de comunicación en general.

- La diferenciación social, cultural y económica de los potenciales migrantes influye poderosamente en el proceso migratorio, la elección del destino, la ocupación futura y el "éxito" migratorio.

- Las redes sociales compuestas por parientes, amigos, vecinos, compañeros de estudios o de trabajo facilitan enormemente y hacen menos traumático el proceso migratorio emprendido por los actores sociales.

Los objetivos que nos propusimos alcanzar fueron:

- Determinar la posición socio-económica de los jóvenes hijos de inmigrantes y conocer su influencia en el proceso migratorio.

\footnotetext{
${ }^{42}$ Arango, J. 2003. Explicación teórica de las migraciones: luz y sombra. En: Migración y desarrollo. No. 1. Octubre. Pp 23
}

- Estudiar las causas, los efectos y los cambios producidos tanto en el lugar de destino como en el de origen de los migrantes.

- Analizar las principales características socioeconómicas de los jóvenes hijos de inmigrantes huancavelicanos asentados en el distrito de Chilca Huancayo.

\section{MATERIALES Y MÉTODOS}

En el presente estudio se empleó principalmente el método comparativo. Se compararon entre sí cada uno de los casos o las historias de vida recogidas para ubicar los aspectos recurrentes y los disímiles, para luego determinar los aspectos universales, generales y particulares.

Población y Muestra.

La población está compuesta por los jóvenes hijos de inmigrantes huancavelicanos asentados en el distrito de Chilca - Huancayo. La muestra fue tomada al azar y está compuesta por aproximadamente 40 jóvenes participantes en los talleres semanales que realiza la ONG UCSICEP, los cuales fueron encuestados y entrevistados.

a) Técnicas y procedimientos de recolección de datos.

La recolección de los datos se realizó a través de la aplicación de una encuesta y del trabajo de campo, instrumentos con los que se procedió a recolectar datos de los familiares de los migrantes y los testimonios de vida (estudios de casos) de los propios jóvenes. En la encuesta se consideraron los siguientes aspectos: datos socio-económicos, tradición familiar, imagen y relaciones con los padres, imágenes y recuerdos de la infancia, escuela, trabajo, imagen de sí mismo, imágenes y percepciones sociales, experiencia religiosa y proyección al futuro; cada uno de los cuales fueron desagregados en subtemas.

b) Técnicas de procesamiento y análisis de datos.

En la labor del procesamiento y análisis de datos se empleó la estadística descriptiva; y en la interpretación de los datos, la inducción y la deducción, el análisis y la síntesis.

c) Materiales y equipos empleados fueron:

Computadora, grabadora, internet, casettes, diskettes, papeles, lapiceros, pilas, libretas de campo.

\section{RESULTADOS}

Con respecto al lugar de procedencia de los jóvenes encuestados y la de sus padres se tiene que el $67.5 \%$ de los emigrantes proviene de alguna provincia de Huancavelica, el $15 \%$ de alguna provincia de Ayacucho, y el $17.5 \%$ de alguna provincia de Junín. Además, cabe resaltar 
que la mayoría de los emigrantes huancavelicanos proviene de las provincias de Pampas Tayacaja y Churcampa.

Otros datos muestran que el $27.5 \%$ de los emigrantes estudia y ayuda en el hogar, el $57.5 \%$ estudia y trabaja, el $12.5 \%$ trabaja, y el $2.5 \%$ no responde.

El $22.5 \%$ de los emigrantes eligió vivir en Huancayo porque consideraban que era un lugar seguro para protegerse de la violencia política, el $42.5 \%$ por las facilidades económicas que otorga, el $17.5 \%$ por las facilidades educativas, el $2.5 \%$ por cuestiones familiares, el $7.5 \%$ por su cercanía, y el $7.5 \%$ no responde.

La información recogida permite afirmar que el $5 \%$ de los padres de los inmigrantes salieron de su lugar de origen porque un familiar suyo ya vivía en Huancayo, el $32.5 \%$ por el terrorismo, el $32.5 \%$ por razones de trabajo, el $17.5 \%$ por razones educativas, y el $12.5 \%$ no sabe.

El $75 \%$ de los inmigrantes tiene a sus tíos y abuelos en sus lugares de origen; el $10 \%$ sólo a sus abuelos; el $10 \%$ a nadie; y el $2 \%$ no responde.

El $37.5 \%$ de las familias tienen cuatro hijos, el $15 \%$ dos, el $12.5 \%$ tres, y el $10 \%$ seis. Pero se han encontrado familias que tienen diez y hasta once hijos.

Por otro lado, el $85 \%$ de los encuestados percibe que ha habido una mejora en los ingresos de la familia luego que decidieran dejar sus localidades frente a un $15 \%$ que percibe que no.

El $42.5 \%$ de los inmigrantes expresa que el motivo que lo impulsaría a salir de Huancayo seria el trabajo, el $10 \%$ por educación, el $20 \%$ por trabajo y estudio, el $2.5 \%$ por el resurgimiento de la violencia política, el $2.5 \%$ por conocer otras culturas, el $5 \%$ por motivos familiares, el $5 \%$ por ningún motivo, y el $12.5 \%$ no responde.

En cuanto al retorno, el $30 \%$ de los inmigrantes muestra su predisposición a retornar a vivir a su lugar de origen, el $65 \%$ no tiene esta predisposición y un $5 \%$ no sabe y no opina.

Asimismo, el $7.5 \%$ de los inmigrantes retorna a su pueblo en vacaciones, el $5 \%$ en la cosecha, el $15 \%$ para visitar a sus familiares, el $50 \%$ en las fiestas patronales y costumbristas, el $7.5 \%$ nunca ha vuelto, y el $15 \%$ no responde.

En cuanto a la ocupación de sus antepasados, el $72.5 \%$ de los abuelos paternos de los inmigrantes fueron agricultores de jóvenes, el $2.5 \%$ mineros, el $2.5 \%$ soldados, el $2.5 \%$ soldadores, el $2.5 \%$ zapateros, el $2.5 \%$ zapateros, el $2.5 \%$ músicos, el $2.5 \%$ albañiles, el $2.5 \%$ negociantes, y el $10 \%$ no sabe.
Igualmente, el $57.5 \%$ de los inmigrantes señalan que sus abuelos maternos trabajaron en la agricultura y la ganadería, el $7.5 \%$ en la minería, el $2.5 \%$ en albañilería, el $15 \%$ fue negociante, el $10 \%$ fue peón, el $2.5 \%$ fue artesano, y el $5 \%$ no sabe.

Hoy en día, del $15 \%$ de los padres de los inmigrantes actualmente trabaja como minero, del $25 \%$ como albañil, del $7.5 \%$ como músico, del $2.5 \%$ como chofer, del $2.5 \%$ como taxista, del $12.5 \%$ ha fallecido, del $10 \%$ como empleado, del $2.5 \%$ como profesor, del $7.5 \%$ como agricultor y ganadero, del $10 \%$ como negociante, del $2.5 \%$ es jubilado, y del $2.5 \%$ como confeccionista.

En cuanto a las relaciones familiares con sus padres, podemos afirmar que el $87.5 \%$ de los emigrantes dice llevarse bien con sus padres, el $12.5 \%$ regular, y mal ninguno.

Sin embargo, el $75 \%$ de los jóvenes manifiesta haber sido castigado físicamente por sus padres y un $25 \%$ no. Sobre la enseñanza, tenemos que el $97.5 \%$ de los inmigrantes enseñaría a sus hijos las enseñanzas recibidas de sus padres y únicamente un $2.5 \%$ no.

En relación a la institución en la que estudiaron los inmigrantes, el $100 \%$ de los inmigrantes estudió en una institución estatal, adicionalmente un $22.5 \%$ en una institución mixta.

En lo que respecta a las relaciones interétnicas, el $52.5 \%$ de los inmigrantes alguna vez se sintió discriminado, el $42.5 \%$ no y el $5 \%$ no sabe no opina. Sin embargo, el $85 \%$ de los inmigrantes considera que existe discriminación racial en nuestro país; el $5 \%$ considera que no y un $10 \%$ no sabe, no opina.

En las cuestiones laborales, un $72.5 \%$ de los inmigrantes acompañó a su padre o a su madre a su trabajo, mientras que un $27 . \% \%$ no lo hizo. El $22.5 \%$ de los inmigrantes empezó a trabajar entre los 05 y los 10 años, el $45 \%$ entre los 11 y 15 años, el $7.5 \%$ entre los 16 y 20 años, y el $25 \%$ no trabajó.

Asimismo, el $20 \%$ de los inmigrantes (mujeres) han trabajado hasta ahora tejiendo, lavando ropa, cocinando, barriendo, cuidando niños, etc., el $2.5 \%$ en carpintería, el $2.5 \%$ como ayudante de carro, el $5 \%$ como obrero de fábrica, el $10 \%$ como negociante, el $2.5 \%$ en la agricultura y ganadería, el $2.5 \%$ en albañilería, el $15 \%$ como peones agrícolas, el $2.5 \%$ como triciclero, el $2.5 \%$ en panadería, el $2.5 \%$ como taxista, el $2.5 \%$ en artesanía, el $7.5 \%$ como dependiente de restaurante o tienda, el $2.5 \%$ como 
empleado de imprenta, y el $20 \%$ no ha trabajado hasta ahora.

Sólo el $7.5 \%$ de los jóvenes hijos de inmigrantes desearía que sus hijos trabaje en la misma labor que ellos desempeñaron; mientras que la mayoría, el $80 \%$ no; y el $7.5 \%$ no sabe no responde.

En cuanto al acceso a los TICs, el $32.5 \%$ de los inmigrantes emplea celular e Internet, el $17.5 \%$ celular, el $35 \%$ Internet y el $15 \%$ ninguno de estos medios de comunicación.

Los porcentajes de las preferencias políticas de los inmigrantes son con sigue: el $5 \%$ de los inmigrantes votó por Alan García en las últimas elecciones presidenciales, el $55 \%$ por Ollanta Humala, el $5 \%$ por otro candidato y el $35 \%$ no responde.

En lo concerniente a los aspectos religiosos, el $87.5 \%$ de los inmigrantes siente la necesidad de relacionarse con Dios, el $7.5 \%$ que no, y el $5 \%$ no sabe, no opina.

Pero, el $27.5 \%$ de los inmigrantes participa en las fiestas religiosas, el $60 \%$ no, el $5 \%$ a veces y el $7.5 \%$ a veces.

En lo relacionado a las creencias tradicionales, el $15 \%$ de los inmigrantes cree en el susto, el chacho y la gargaria; el $27.5 \%$ en el susto y el chacho; el $2.5 \%$ en el susto y la gargaria; el $5 \%$ en el chacho y la gargaria; el $7.5 \%$ en el susto; el $5 \%$ en el chacho; el $2.5 \%$ en la gargaria; el $25 \%$ en ningunos; y finalmente un $10 \%$ no sabe no opina. Por otra parte, el $37.5 \%$ de los inmigrantes llevaría a sus familiares donde un curandero, el $50 \%$ no, el $10 \%$ no sabe no opina y el $2.5 \%$ dice "puede ser", "más o menos."

Finalmente, en el futuro, el $52.5 \%$ de los inmigrantes se imagina como un profesional, el 17.5\% habiendo progresado, el 2,5\% con un negocio, el $7.5 \%$ más viejo, el $5 \%$ con trabajo, el $7.5 \%$ no sabe, y el $7.5 \%$ no responde.

\section{DISCUSIÓN}

La información recogida nos permite afirmar que la mayoría de los jóvenes hijos de inmigrantes huancavelicanos asentados en el distrito de Chilca provienen, de los distritos de Huancavelica, principalmente de las provincias de Tayacaja y Churcampa. Aquí es preciso tener presente que Huancavelica es considerado como el departamento más pobre de nuestro país. La mayoría de los inmigrantes han llegado a Huancayo debido a su cercanía, limita con Tayacaja. En el caso de los churcampinos, debido, a que están conectados económicamente a Huancayo, venden su producción agropecuaria y se aprovisionan de productos industriales y manufacturados en ella. Además, es más fácil llegar de estos lugares a Huancayo que a Huancavelica, la capital departamental.
Un dato importante que se desprende de los datos empíricos recogidos es que la mayoría de los jóvenes hijos de inmigrantes huancavelicanos tienen estudios secundarios, en comparación a la situación a la generación de sus padres que en su mayoría eran analfabetos, tenían educación primaria incompleta o primaria completa cuando abandonaron sus localidades de origen.

La mayoría de los padres de los hijos de los inmigrantes huancavelicanos son casados, lo cual es un indicador de la importancia de la familia para este sector de la población, no solamente como proveedora de recursos económicos sino también de control, reconocimiento, valores y soporte emocional; elementos fundamentales en la formación integral de cualquier adolescente o joven.

Un buen porcentaje de los jóvenes señala haberse asentado definitivamente en Huancayo, lo que quiere decir que cualquier acción orientada a ayudarlos a salir de la situación de pobreza en la que se encuentran debe hacerse en Huancayo y no en sus localidades de origen.

La familia nuclear es importante en los inmigrantes huancavelicanos, pero se demuestra también la relativa importancia que aún tiene la familia extensa en un nuevo contexto como es la ciudad, ya que entre sus miembros se tejen un conjunto de relaciones sociales de solidaridad y reciprocidad que, tal como lo han demostrado un sinnúmero de estudios, juegan un papel trascendental en situaciones de pobreza, marginalidad y exclusión social.

De la información recogida se puede colegir que la mayoría de los padres huancavelicanos de estos jóvenes e incluso ellos mismos, llegaron a Huancayo en el período en el que nuestro país atravesaba por una seria crisis económica y un brutal enfrentamiento entre peruanos como consecuencia de la violencia política. De un lado, con las fuerzas armadas y policiales defendiendo el orden establecido; y por otro, los subversivos tratando de destruirlo, y con la sociedad civil al medio.

La mayoría de los jóvenes aún tienen familiares y parientes en sus lugares de origen, este aspecto hace que eventualmente viajen a sus localidades para visitarlos, de este modo, no rompen totalmente los nexos con sus pueblos. Podemos intuir que aquellos que ya no tienen parientes en sus pueblos llegan a romper estos nexos.

En cuanto al número de integrantes de las familias, podemos afirmar que los miembros de las familias de los inmigrantes huancavelicanos son muy numerosos, por ello, dada la situación de precariedad económica en la que viven es imaginable los serios problemas que deben enfrentar para poder sobrevivir. 
De alguna manera, la mitad de las viviendas de las familias de los inmigrantes huancavelicanos cuenta con los servicios básicos, este es el caso de las que se han asentado desde hace mucho tiempo atrás. De seguro, es posible que las viviendas de los que han llegado recientemente no cuenten con estos servicios o cuenten con sólo algunos de ellos.

De igual modo, es posible que las viviendas de los asentados más antiguos sean propias y los que llegaron posteriormente vivan en viviendas alquiladas o las habiten como cuidadores.

A pesar de haber manifestado hallarse definitivamente asentados en la ciudad de Huancayo, un porcentaje significativo muestra su predisposición a salir de Huancayo por diversos motivos.

La mayoría de los padres de los jóvenes, antes de migrar, cuando eran jóvenes, se dedicaban, en orden de importancia, a la agricultura y la ganadería, al peonaje, a la albañilería y la minería (obrero). De todos modos ya se puede notar una cierta diversificación ocupacional que es una muestra de los cambios que ya se venían produciendo en sus localidades en el tiempo que les tocó vivir.

Los abuelos tanto paternos como maternos de los jóvenes se dedicaban fundamentalmente a la agricultura y la ganadería. Esta situación cambia significativamente en el caso de los padres y los propios jóvenes, en los que podemos notar una mayor diversificación ocupacional. Además, es un síntoma de los cambios que se han ido produciendo en cada una de estas generaciones y de cómo las relaciones sociales y culturales se complejizan ya que son ocupaciones urbanas.

Un aspecto resaltante de las manifestaciones de los jóvenes es la persistencia del castigo físico en un considerable número de casos, esto explicaría los altos índices de violencia familiar en este sector de la población.

La mayoría de los jóvenes gasta sus ingresos en educación, contribuye en los gastos de su casa, compra ropa y golosinas y entrega a sus padres.

Es significativo el número de jóvenes que no desean que sus hijos trabajen en la misma labor que ellos han realizado, porque no quieren que "sufran" como ellos, que "pasen lo que yo he pasado". Aquí podemos encontrar percepciones de lo que entienden por lo que es la superación, el mejoramiento y el progreso en general.

Gracias a los medios de comunicación electrónicos, los jóvenes acceden a formas simbólicas ajenas a su localidad que les sirven de insumo para construir sus sueños, sus esperanzas, sus proyectos de vida, su cosmovisión; en términos concretos influyen en la construcción de su identidad. Es más les permite estar en contacto con sus familiares que se pudieran haber quedado en su pueblo natal, de existir Internet en él y con los que pudieran estar en el extranjero.

Cuando los individuos participan en las fiestas religiosas (ceremoniales, rituales), reafirman su fe en el orden moral del que depende la solidaridad del grupo. Los ritos positivos que entraña el ceremonial religioso proporcionan así una consolidación moral del grupo, que se repite regularmente; consolidación necesaria, porque en las actividades de la vida diaria en el mundo profano los individuos buscan sus propios intereses egoístas y, por tanto, están expuestos a desentenderse de los valores morales de los que depende la solidaridad de la sociedad. ${ }^{43}$

\section{CONCLUSIONES}

- La emigración de los jóvenes huancavelicanos fue provocada por una serie de factores internos que afectaron nuestro país y la región Huancavelica en particular: la pobreza y condición económica de la población; la violencia política de las décadas de los 80' y los 90 , el prejuicio social o religioso; la superpoblación en relación a los recursos disponibles, etc. Todo fenómeno de este tipo constituye lo que en conjunto se ha llamado los factores que "empujan" a las personas afectadas, dándoles la razón para salir de sus pueblos de origen.

- A la misma vez que operan los factores de "empuje" también intervienen otras variables que los suplementan, agregando una dimensión que destaca las fuentes de descontento en la sociedad. Estos son los anhelos individuales o del grupo para mejorar su condición social y su nivel de vida que inspiran la inquietud y que rechazan así mismo la idea que el porvenir será igual al presente. Dichas inquietudes se deben a conocimientos y creencias de que existen en otros lugares, mejores medios y oportunidades aprovechables. De tal manera, esas razones son las que "jalan" a las personas de su terruño. También los factores de "jale" les indican usualmente, el destino donde el flamante el joven inmigrante huancavelicano realizará sus deseos, haciendo realidad sus sueños. ${ }^{44}$

- Los motivos que han "empujado" a migrar a los padres de los jóvenes huancavelicanos son principalmente, buscar nuevas fuentes de trabajo y una vida nueva, huir de la violencia política y acceder a servicios educativos de calidad, dejando tras de ellos sus lugares de origen

\footnotetext{
${ }^{43}$ Durkheim, Emile. 1982. Las formas elementales de la vida religiosa. Madrid: Akal. Pp 234

${ }^{44}$ Doughty, P. L. 1964. La migración provinciana, regionalismo y el desarrollo local. En: Economía y agricultura. Vol. I, Número 3, Lima. Pp 205
} 
en las que vivían en situaciones que no les permitían la movilidad social o que sufrían prejuicios contra sus personas por motivos religiosos o culturales. La gran mayoría son gente pobre: entre ellos muchos analfabetos y semianalfabetos, y personas que llegaron a veces sin un centavo en sus bolsillos, especialmente, aquellos que llegaron huyendo de la violencia política (los desplazados). Pero, en general casi todos llegaron con grandes aspiraciones.

- Los que han salido principalmente son los más educados, los más acomodados y los más aculturados, o sea los que tienen mayor preparación para participar en la vida moderna de las ciudades ${ }^{45}$. Este sector de la población es, sobre todo, masculina y mayor de 15 años de edad.

- La migración llama primero a los hombres por varias razones, entre ellas su obligación de buscar la manera de sostener a su familia, lo que lo obliga a ir a lugares donde hay fuentes de trabajo. Segundo, porque el hombre serrano generalmente se encuentra mejor instruido que la mujer, especialmente en las zonas rurales, y es más "mosca" para poder aprovechar las oportunidades que se le presentan.

- No obstante del afán de realizar sus anhelos personales, también existe un marcado interés en los inmigrantes para que sus pueblos progresen, salgan adelante; están dispuestos a contribuir con ello. Esto constituye el tema más generalizado en la vida de los jóvenes emigrantes asentados en al ciudad de Huancayo.

\section{REFERENCIAS BIBLIOGRÁFICAS}

- $\quad$ Arango, J. Explicación teórica de las migraciones: luz y sombra. En: Migración y desarrollo. No. 1. Octubre. 2003.

- $\quad$ Doughty, P. L. La migración provinciana, regionalismo y el desarrollo local. En: Economía y agricultura. Vol. I, Número 3, Lima. 1964.

- Durkheim, Emile. Las formas elementales de la vida religiosa. Madrid: Akal. 1982.

\footnotetext{
${ }^{45}$ Ibidem, pp 207
} 